\title{
A Model for the Determination of Diffusion Capacity Under Non-Standard Temperature and Pressure Conditions*
}

\begin{abstract}
Published in modified form as presentation ST34 at the CORESTA SSPT Study Groups' Meeting in Sevilla, Spain, September 30-October 3, 2013.
\end{abstract}

by

Bernhard Eitzinger

delfortgroup AG, Fabrikstrasse 20, 4050 Traun, Austria

\section{SUMMARY}

The diffusion capacity of cigarette paper has been reported to be an important parameter in relation to the self-extinguishment of cigarettes and also in relation to carbon monoxide yields. Although the diffusion capacity is routinely measured and instruments for this measurement have been available for several years, differences between measured values obtained on the same paper sample but on different instruments or in different laboratories may be substantial and may make it difficult to use these values, for example, as a basis for paper specifications. Among several reasons, deviations of temperature and pressure from standard conditions, especially within the measurement chamber of the instrument, may contribute to the high variation in diffusion capacity data. Deviations of temperature and pressure will have an influence on the gas flow rates, the diffusion processes inside the measurement chamber and consequently the measured $\mathrm{CO}_{2}$ concentration. Generally, the diffusion capacity is determined from a mathematical model, which describes the diffusion processes inside the measurement chamber. Such models provide the $\mathrm{CO}_{2}$ concentration in the outflow gas for a given diffusion capacity. For practical applications the inverse model is needed, that is, the diffusion capacity shall be determined from a measured $\mathrm{CO}_{2}$ concentration. Often such an inverse model is approximated by a polynomial, which, however, is only valid for standard temperature and pressure.
It is shown that relative approximation errors from such polynomials, even without temperature and pressure deviations, cannot always be neglected and it is proposed to eliminate such errors by direct inversion of the model with a comparably simple iterative method.

A model which includes temperature and pressure effects is described and the effects of temperature and pressure deviations on the diffusion capacity are theoretically estimated by comparing the output of a model with and without inclusion of temperature and pressure effects. The results suggest that these effects may cause relative differences in the diffusion capacity up to $50 \%$ for pressure and temperature ranges of practical relevance. [Beitr. Tabakforsch. Int. 26 (2014) 50-56]

\section{ZUSAMMENFASSUNG}

Die Diffusionskapazität des Zigarettenpapiers hat sich sowohl in Bezug auf die Selbstverlöschung von Zigaretten als auch in Bezug auf den Gehalt an Kohlenmonoxid als wichtiger Parameter erwiesen. Obwohl die Diffusionskapazität von Zigarettenpapieren schon mehrere Jahre routinemäßig gemessen wird, und Messgeräte dafür verfügbar sind, können die Differenzen zwischen Werten, die auf demselben Papier aber auf unterschiedlichen Geräten oder in unterschiedlichen Laboratorien gemessen wurden, erheblich sein, und es kann daher schwierig sein, diese Werte beispielsweise als Basis für Spezifikationen 
des Papiers zu verwenden. Neben einigen anderen Ursachen können Abweichungen in Temperatur und Druck von den Standardbedingungen, insbesondere innerhalb der Messkammer, zur hohen Streuung in Diffusionskapazitätsdaten beitragen. Abweichungen in Temperatur und Druck beeinflussen die Strömungsgeschwindigkeit der Gase, die Diffusionsprozesse innerhalb der Messkammer und daher auch die gemessenen $\mathrm{CO}_{2}$-Konzentrationen.

Im Allgemeinen wird die Diffusionskapazität mit Hilfe eines mathematischen Modells bestimmt, das die Diffusionsprozesse in der Messkammer beschreibt. Solche Modelle liefern die Konzentration von $\mathrm{CO}_{2}$ im ausströmenden Gas für eine gegebene Diffusionskapazität. In der praktischen Anwendung aber wird das inverse Modell benötigt, das heißt, die Diffusionskapazität soll aus einer gemessenen $\mathrm{CO}_{2}$-Konzentration bestimmt werden. Dies wird oft mittels einer Näherung des inversen Modells durch ein Polynom erreicht, das dann aber nur für Standardbedingungen gültig ist.

Es zeigt sich, dass die relativen Näherungsfehler solcher Polynome, selbst ohne Abweichungen in Temperatur und Druck, nicht immer vernachlässigbar sind und es wird vorgeschlagen, diese Fehler durch direkte Inversion des Modells mittels eines vergleichsweise einfachen numerischen Verfahrens zu eliminieren.

Ein Modell, das Temperatur- und Druckeffekte enthält, wird beschrieben und die Effekte von Abweichungen in Temperatur und Druck auf die Diffusionskapazität werden theoretisch abgeschätzt, indem die Ergebnisse eines Modells mit und ohne Berücksichtigung der Temperaturund Druckeffekte verglichen werden. Die Ergebnisse zeigen, dass diese Effekte in einem praktisch relevanten Temperatur- und Druckbereich erhebliche Differenzen in der Diffusionskapazität von bis 50\% verursachen können. [Beitr. Tabakforsch. Int. 26 (2014) 50-56]

\section{RESUME}

La capacité de diffusion du papier à cigarettes est un paramètre important en ce qui concerne l'extinction spontanée des cigarettes ainsi que la concentration de monoxyde de carbone.

Depuis plusieurs années on mesure périodiquement la capacité de diffusion des papiers à cigarettes, les appareils de mesure en sont disponibles, quand même le procédé de reprise et de reproduction de cette méthode de mesure n'est pas entièrement satisfaisant. Les valeurs obtenues mesurées sur le même papier, mais à l'aide des appareils ou dans des laboratoires différents peuvent être considérables. Ainsi, il est difficile de se servir de ces valeurs, par exemple pour les effets spéciaux du papier.

En plus de quelques autres raisons, des erreurs en température et en pression de la condition standard, avant tout à l'intérieur de la chambre à mesure, peuvent contribuer à une variation considérable des résultats de capacité de diffusion. En générale, on détermine la capacité de diffusion à l'aide d'une interprétation théorique qui démontre les processus de diffusion à l'intérieur de la chambre à mesure. Des erreurs en température et en pression influencent la vitesse des flux de gaz, les processus de diffusion à l'intérieur de la chambre à mesure, et - par conséquent les concentrations $\mathrm{CO}_{2}$ évaluées.

Un tel modèle mathématique permet d'évaluer la concentration $\mathrm{CO}_{2}$ pour une capacité de diffusion donnée. Habituellement, on applique une approximation sous forme d'un polynôme, mais seulement pour des conditions standard. Ainsi, les erreurs d'approximation de tels polynômes ne peuvent pas toujours être négligées. On propose d'inverser le modèle, à l'aide d'une opération numérique simple, pour que les erreurs d'approximation puissent être éliminées. Un modèle - y compris les effets de température et de pression - est décrit et les effets causés par des erreurs en température et en pression sont évalués théoriquement en comparant les résultats d'un modèle avec et sans regard des effets de température et de pression.

Les résultats démontrent que ces effets - en respectant la température et la pression - pourraient causer des différences considérables jusqu'à $50 \%$ de la capacité de diffusion. [Beitr. Tabakforsch. Int. 26 (2014) 50-56]

\section{INTRODUCTION}

The diffusion capacity of cigarette paper has been reported to be an important parameter in relation to the self-extinguishment of cigarettes $(1,2)$ and also in relation to carbon monoxide yields (3). Instruments to measure the diffusion capacity of cigarette papers are mainly based on a concept developed by DRAKE et al. in 1980 (4) and several instruments are now commercially available. Recently, efforts have been undertaken to standardize the measurement of diffusion capacity in a CORESTA Recommended Method (5). In the development of this Recommended Method it was found that differences between values obtained on different instruments or in different laboratories are rather high compared, for example, with the measurement of air permeability. A substantial portion of this variation can be attributed to different instrument concepts and to the fact that no reference standard material is available to calibrate these instruments. However, deviations from the standard temperature of $296.15 \mathrm{~K}$ defined for the testing of paper in ISO 187 (6) and from a standard pressure of $101.325 \mathrm{kPa}$ may also have a certain influence on the variation of diffusion capacity data and shall be the subject of this study.

The principle of diffusion capacity measurement is shown in Figure 1. A paper sample divides the measurement chamber in two nominally identical compartments, each of depth $\mathrm{t}$, and exposes a rectangular area $\mathrm{a} \times \mathrm{b}$ of paper to diffusion. In the upper compartment nitrogen $\left(\mathrm{N}_{2}\right)$ is flowing parallel to the paper surface, while in the lower compartment carbon dioxide $\left(\mathrm{CO}_{2}\right)$ is flowing in the same direction as the nitrogen flow, but along the other side of the paper. During the time the two gases are flowing along the paper surface, they can pass through the paper by diffusion. It is important to keep the pressure difference between both sides of the paper as low as possible, otherwise a pressure driven gas transport as in an air permeability measurement would take place. The mixture of $\mathrm{N}_{2}$ and $\mathrm{CO}_{2}$ flowing out of the measurement chamber is passed on to a gas analyser where the volumetric $\mathrm{CO}_{2}$ concentration in the $\mathrm{N}_{2}$ flow is measured and from this $\mathrm{CO}_{2}$ concentration the diffusion capacity of the paper is calculated. 


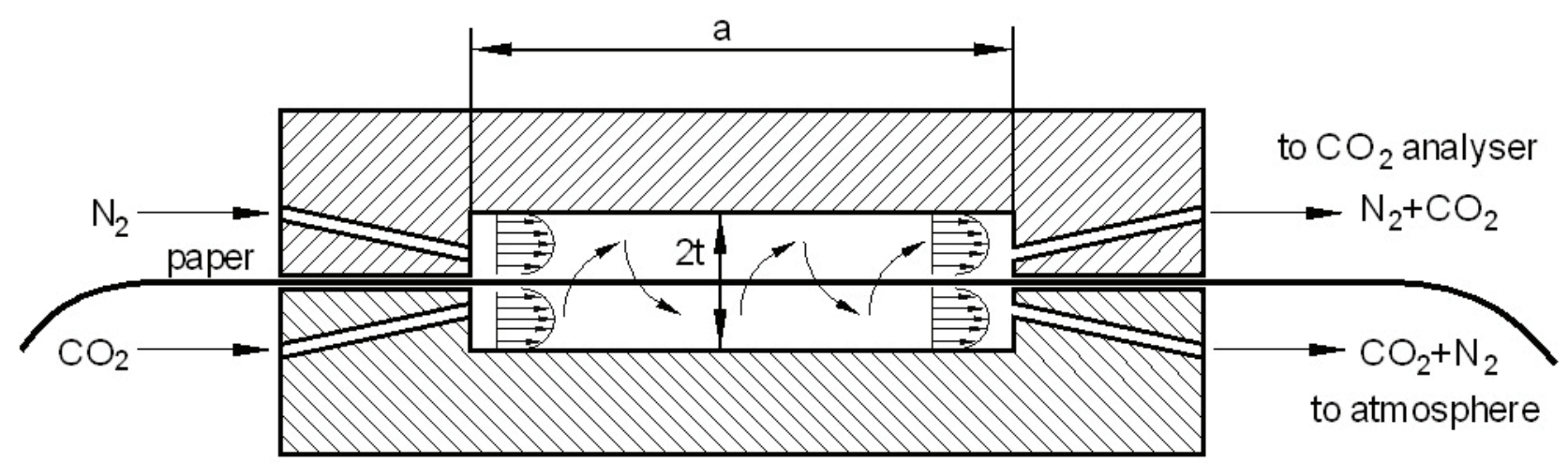

Figure 1. Cross section of the measurement chamber. The paper sample divides the measurement chamber in two compartments and exposes a rectangular area of $a \times b$ of paper, $b$ orthogonal to the cross section, to diffusion.

The calculations are based on a model which describes the flow and diffusion process in the measurement chamber. This model, however, provides the $\mathrm{CO}_{2}$ concentration in the outflow gas for a given diffusion capacity as output and not - as would be needed for a measurement instrument - the diffusion capacity for a given $\mathrm{CO}_{2}$ concentration. For that purpose an inverse of the mathematical model is needed. Frequently, the model has the form of a set of partial differential equations, which can be solved analytically by expansion to an infinite series. Such a series, even if truncated after a few elements, does not have an analytical inverse, so that a polynomial is fitted to a set of corresponding pairs of $\mathrm{CO}_{2}$ concentrations and diffusion capacities obtained from the model. Such polynomials allow a straightforward calculation of the diffusion capacity from the measured volumetric $\mathrm{CO}_{2}$ concentration, but they have the main disadvantage that they contain only the $\mathrm{CO}_{2}$ concentration as a variable and do not allow the variation of other parameters, such as the measurement chamber geometry, flow rates and temperature or pressure, without resorting to the original model from which these polynominals were derived.

Consequently, variations in parameters such as temperature and pressure cannot be compensated in this calculation process, even though they may have a substantial influence on the diffusion capacity.

It is a goal of this study first, to evaluate the magnitude of the errors introduced by the polynomial approximation and, second, to theoretically evaluate differences caused by deviations of temperature and pressure from standard conditions by comparing the output of two calculation models, of which one does and the other does not include temperature and pressure effects.

\section{MATHEMATICAL MODEL}

The starting point is a model proposed to relate diffusion capacity and $\mathrm{CO}_{2}$ concentration in the outflowing gas as derived by DRAKE et al. (4) and the polynomial for inversion as determined by NORMAN et al. (7). The partial differential equation derived by DRAKE et al. allows an analytic solution in the form of a series expansion, which is repeated here.

$$
\begin{gathered}
\beta=\frac{2 t}{D_{g}} D^{*} \\
\gamma=\frac{a b}{V} \frac{D_{g}}{6 t} \\
\chi=2 \beta^{2} \sum_{i=1}^{10} \frac{e^{-6 \gamma \alpha_{i}^{2}}}{\alpha_{i}^{2}\left(\alpha_{i}^{2}+\beta^{2}+\beta\right)} \\
C_{C O 2, \text { out }}=C_{C O 2, \text { in }} \frac{(1-\chi)}{2}
\end{gathered}
$$

where $\alpha_{i}$ are the 10 smallest solutions of $\beta=\alpha_{i} \tan \left(\alpha_{i}\right)$. The parameters $a, b$, and $t$ describe chamber length, width and depth, $\mathrm{V}$ is the volumetric flow rate through the chamber, $\mathrm{D}_{\mathrm{g}}$ is the free gas diffusion coefficient of $\mathrm{CO}_{2}$ in $\mathrm{N}_{2}, \mathrm{D}^{*}$ is the diffusion capacity and $\mathrm{C}_{\mathrm{CO} \text {, in }}$ and $\mathrm{C}_{\mathrm{CO} \text {,out }}$ are the volumetric $\mathrm{CO}_{2}$ concentrations in the $\mathrm{CO}_{2}$ flowing into the chamber and in the $\mathrm{N}_{2}$ flowing out of the chamber, respectively.

Several of these parameters depend on temperature and pressure and for each of these parameters their dependence will be discussed in the following.

\section{Temperature and pressure range}

For this theoretical investigation a temperature range from $288 \mathrm{~K}$ to $304 \mathrm{~K}$ will be considered. The standard temperature according to ISO 187 (6) is $296.15 \mathrm{~K}$, but laboratory conditions and especially conditions in a production environment may deviate from the standard temperature, often simply for practical reasons. Furthermore the relevant temperature in this investigation is the gas temperature in the measurement chamber, which may be higher or lower than the standard temperature even in a controlled laboratory environment, as the gases may be supplied from containers stored outside the laboratory or the gases may flow in tubing running inside the instrument where they are unintentionally heated.

The range of pressures was chosen from $85 \mathrm{kPa}$ to $105 \mathrm{kPa}$, while the standard pressure is $101.325 \mathrm{kPa}$. Weather and altitude are the main influences on the ambient pressure and 
as cigarette factories are located as high as $1800 \mathrm{~m}$, the limits were chosen to cover typical conditions from sea level up to this altitude.

Apart from the standard conditions of $296.15 \mathrm{~K}$ and $101.325 \mathrm{kPa}$, three temperature and pressure pairs will be used for the calculations. These are $\mathrm{T}=304 \mathrm{~K}, \mathrm{p}=85 \mathrm{kPa}$; $\mathrm{T}=296.15 \mathrm{~K}, \mathrm{p}=85 \mathrm{kPa}$; and $\mathrm{T}=288 \mathrm{~K}, \mathrm{p}=105 \mathrm{kPa}$. The combinations of high temperature/low pressure and low temperature/high pressure were chosen as they will provide the maximum effect on the diffusion capacity within the investigated temperature and pressure range. The third pair, $296.15 \mathrm{~K}$ and $85 \mathrm{kPa}$, is chosen to isolate pressure effects, as temperature is often controlled in laboratories, while ambient pressure is not.

\section{Volumetric flow rate}

For a given mass flow, the volumetric flow rate of a gas depends on temperature and pressure. As the volumetric flow rate determines the time the gas molecules need to flow along the paper surface and hence the time available for gas exchange by diffusion, it has a substantial influence on the resulting $\mathrm{CO}_{2}$ concentration and the diffusion capacity. It is therefore preferred to establish a constant volumetric gas flow by instrumental means, instead of compensating errors by calculation. Consequently, it shall be assumed here that the flow rate is set such that the volumetric flow rate in the measurement chamber under the temperature and pressure conditions in the chamber matches its nominal value.

\section{Chamber geometry}

The chamber geometry is affected by temperature through thermal expansion of the material from which the measurement chamber is made. In the case of steel the coefficient of thermal expansion is about $\alpha=10^{-5}(8)$. The change in chamber geometry due to temperature effects can in good approximation be modelled by

$$
\frac{a}{a_{0}}=1+\alpha\left(T-T_{0}\right)
$$

with $\mathrm{T}$ being the actual temperature of the measurement chamber and $\mathrm{T}_{0}=296.15 \mathrm{~K}$ being the standard temperature and with $\mathrm{a}_{0}$ being the corresponding length at standard temperature. The same holds for other chamber dimensions such as width $b$ and depth t. Further analysis, however, shows that thermal expansion of the measurement chamber has a very small effect on diffusion capacity. An evaluation of equation [5] shows a relative dimensional change of less than $0.01 \%$ and the model, considering the effect of thermal expansion in isolation, shows relative changes in the diffusion capacity of less than $0.1 \%$ for the temperature range under investigation. Therefore this effect could also be neglected, but as it can be incorporated in the model easily, it is retained.

The chamber geometry will also depend on the pressure by elastic deformation. Due to the high elastic modulus of steel, the resulting effect is orders of magnitude smaller than temperature effects and can be safely neglected.
An increase in temperature leads to an increase in the chamber dimensions. At constant volumetric flow rate the gases will be flowing more slowly along the paper, which allows more time for gas exchange by diffusion and therefore increases diffusion capacity values.

\section{Free gas diffusion}

Diffusion processes depend on molecular motion and are highly dependent on temperature and pressure. As free diffusion occurs in the measurement chamber in the space above and below the paper surface and in the paper pores, these effects cannot be neglected. Data reported in the past (8) shows a non-linear dependence on temperature and an inverse dependence on pressure, so that the resulting equation is as follows

$$
D_{g}(T, p)=D_{g_{0}}\left(\frac{T}{T_{0}}\right)^{n} \frac{p_{0}}{p}
$$

with $p$ being the actual pressure in the chamber, $\mathrm{p}_{0}=101.325 \mathrm{kPa}$ being the standard pressure and $\mathrm{n}$ being an exponent, which, derived from literature data (8), can be set to 1.88. The free gas diffusion coefficient of $\mathrm{CO}_{2}$ in $\mathrm{N}_{2}$ at standard conditions is denoted by $\mathrm{D}_{\mathrm{g} 0}$ and is assigned a value of $0.163 \mathrm{~cm}^{2} \cdot \mathrm{s}^{-1}$.

Results of a numerical evaluation of equation [6] for various temperature and pressure combinations are given in Table 1 and show that relative changes of the free gas diffusion coefficient between $-8.4 \%$ and $25.2 \%$ can be expected.

At higher temperatures or lower pressures free gas diffusion occurs faster. Therefore the gases are transported more quickly away from the paper surface, so that the $\mathrm{CO}_{2}$ concentration difference between both sides of the paper remains high and more gas can diffuse through the paper.

Table 1. The free gas diffusion coefficient of $\mathrm{CO}_{2}$ in $\mathrm{N}_{2}$ for various temperature pressure combinations and its change relative to the value at standard conditions.

\begin{tabular}{l|c|c|c}
\hline $\begin{array}{l}\text { Temperature } \\
(\mathrm{K})\end{array}$ & $\begin{array}{c}\text { Pressure } \\
(\mathrm{kPa})\end{array}$ & $\begin{array}{c}\mathrm{D}_{\mathrm{g}}(\mathrm{T}, \mathrm{p}) \\
\left(\mathrm{cm}^{2} \cdot \mathrm{s}^{-1}\right)\end{array}$ & $\begin{array}{c}\text { Relative change } \\
(\%)\end{array}$ \\
\hline 304.00 & 85.000 & 0.204 & 25.2 \\
296.15 & 85.000 & 0.194 & 19.2 \\
296.15 & 101.325 & 0.163 & \\
288.00 & 105.000 & 0.149 & -8.4 \\
\hline
\end{tabular}

\section{Diffusion capacity}

The diffusion capacity is determined by diffusion processes in the paper pores, which comprise free diffusion in large pores and Knudsen diffusion in small pores, where "large" and "small" have to be interpreted in relation to the mean free path length of a gas molecule. Free diffusion in large pores depends on temperature and pressure in the same way as the free gas diffusion outside of pores. In the small pores, however, collisions between gas molecules and the pore walls dominate over the molecule-molecule collisions. Therefore Knudsen diffusion is not pressure-dependent. 
Assuming that each pore contributes to the total diffusive flow either by Knudsen diffusion or by free diffusion these contributions can be superposed, so that as a result the temperature and pressure dependence of the diffusion capacity can be modelled as follows.

$$
D^{*}(T, p)=D_{0}^{*}\left(\kappa \sqrt{\frac{T}{T_{0}}}+(1-\kappa)\left(\frac{T}{T_{0}}\right)^{n} \frac{p_{0}}{p}\right)
$$

where $\kappa$ is the share of Knudsen diffusion in the total diffusion and $\mathrm{D}_{0}^{*}$ is the diffusion capacity at standard conditions. Based on permeability measurements of cigarette papers with different gases an estimate of $\kappa=0.034$ is obtained (9). Although there may be some uncertainty in the value of $\kappa$ and some dependence on the type of cigarette paper, the results depend very little on the precise value.

An evaluation of equation [7] for various temperature and pressure combinations is given in Table 2. The results suggest that diffusion capacity itself may have a substantial temperature and pressure dependence with the relative changes from $-8.2 \%$ up to $24.4 \%$ being similar to the changes of the free gas diffusion coefficient.

Clearly, if the temperature rises or the pressure is reduced, diffusion becomes faster, more gas diffuses through the cigarette paper and the diffusion capacity reading will be higher than under standard conditions.

The complete model, which includes temperature and pressure effects, is now composed of equations [1-4], where the temperature and pressure dependence is included as given in equations [5-7].

This mathematical model needs as input the diffusion capacity $\mathrm{D}_{0}^{*}$ under standard conditions and the actual temperature $\mathrm{T}$ and pressure $\mathrm{p}$ in the measurement chamber and it delivers the $\mathrm{CO}_{2}$ concentration in the $\mathrm{N}_{2}$ flow as output.

Table 2. The relative change in diffusion capacity for various temperature and pressure combinations.

\begin{tabular}{l|c|c}
\hline $\begin{array}{l}\text { Temperature } \\
(\mathrm{K})\end{array}$ & $\begin{array}{c}\text { Pressure } \\
(\mathrm{kPa})\end{array}$ & $\begin{array}{c}\text { Relative change } \\
(\%)\end{array}$ \\
\hline 304.00 & 85.000 & 24.4 \\
296.15 & 85.000 & 18.5 \\
296.15 & 101.325 & \\
288.00 & 105.000 & -8.2 \\
\hline
\end{tabular}

\section{Numerical evaluation of the model}

Due to the simplicity of the model it was implemented in Excel ${ }^{\circledR}$ with a macro used to solve the non-linear equation $\beta=\alpha_{\mathrm{i}} \tan \left(\alpha_{\mathrm{i}}\right)$ by a bisection method to an absolute error in $\alpha_{i}$ of less than $10^{-14}$. The model was evaluated for 25 different diffusion capacity values between $\mathrm{D}_{0}^{*}=0 \mathrm{~cm} \cdot \mathrm{s}^{-1}$ and $\mathrm{D}_{0}^{*}=3 \mathrm{~cm} \cdot \mathrm{s}^{-1}$ at the standard conditions of $\mathrm{T}_{0}=296.15 \mathrm{~K}$ and $\mathrm{p}_{0}=101.325 \mathrm{kPa}$. The volumetric flow rate was set to $\mathrm{V}=7.5 \cdot 10^{-6} \mathrm{~m}^{3} \cdot \mathrm{s}^{-1}$, which corresponds to a flow rate of $450 \mathrm{~mL} \cdot \mathrm{min}^{-1}$. The chamber dimensions were set to a length of $a_{0}=20 \mathrm{~mm}$, a width of $b_{0}=3 \mathrm{~mm}$ and a depth of $\mathrm{t}_{0}=1.75 \mathrm{~mm}$. At the inlet the volumetric concentration of $\mathrm{CO}_{2}$ was $\mathrm{C}_{\mathrm{CO} 2 \text {,in }}=100 \%$. A polynomial was fitted in the least-squares sense to the 25 pairs of $\mathrm{CO}_{2}$ concentrations $\mathrm{C}_{\mathrm{CO} \text {,out }}$ and diffusion capacity values $\mathrm{D}_{0}^{*}$, which allows the direct calculation of an estimated diffusion capacity $\mathrm{D}_{\text {est }}^{*}$ from a measured $\mathrm{CO}_{2}$ concentration $\mathrm{C}_{\mathrm{CO} 2 \text {,out }}$ by

$$
\begin{gathered}
D_{\text {est }}^{*}=0.004873+0.107505 \times C_{C O 2, \text { out }} \\
+0.019272 \times C_{C O 2, \text { out }}^{2}-0.0024697 \times C_{C O 2, \text { out }}^{3} \\
+0.00025702 \times C_{C O 2, \text { out }}^{4}
\end{gathered}
$$

where $\mathrm{C}_{\mathrm{CO} \text {,out }}$ has to be entered in percent, i.e., $0-100$, and $\mathrm{D}_{\mathrm{est}}^{*}$ is obtained in $\mathrm{cm} \cdot \mathrm{s}^{-1}$. It has to be noted that polynomial [8] is only applicable if the conditions in the measurement chamber $\mathrm{T}$ and $\mathrm{p}$ match the standard conditions of $296.15 \mathrm{~K}$ and $101.325 \mathrm{kPa}$, in practice however, such polynomials are often also used when this requirement is not fulfilled and, as will be shown below, the differences may be considerable.

To evaluate the effect of temperature and pressure deviations from standard conditions, the model of equations [1-7], i.e., including all temperature and pressure effects, was used to calculate $\mathrm{CO}_{2}$ concentrations in the $\mathrm{N}_{2}$ flowing out of the measurement chamber for the same 25 diffusion capacity values, but for the three different temperature and pressure pairs mentioned further above. From these $\mathrm{CO}_{2}$ concentrations the diffusion capacity values were calculated by polynomial [8] and represent the values obtained without any inclusion of temperature and pressure effects, while the values which were originally used as input for the model [1-7] are considered as the true diffusion capacity values.

\section{RESULTS}

Figure 2 shows as a dashed line the relative error between the true diffusion capacity and the diffusion capacity estimated from polynomial [8], i.e., it shows the relative approximation error of the polynomial. The solid lines show the relative differences between the true diffusion capacity and the diffusion capacity calculated from polynomial [8] for various temperature and pressure combinations.

\section{DISCUSSION}

\section{Approximation error}

Although the absolute errors in the diffusion capacity values due to the polynomial approximation are always less than $0.005 \mathrm{~cm} \cdot \mathrm{s}^{-1}$, diffusion capacities of the bands on lower ignition propensity cigarette papers can be as low as $0.05 \mathrm{~cm} \cdot \mathrm{s}^{-1}$, which means a relative error of up to $10 \%$. Thus, even without any temperature or pressure deviations a source of errors is introduced by approximating the inverse of model [1-7] with a polynomial, which may not always be negligible. Also, changes in the instrumental 


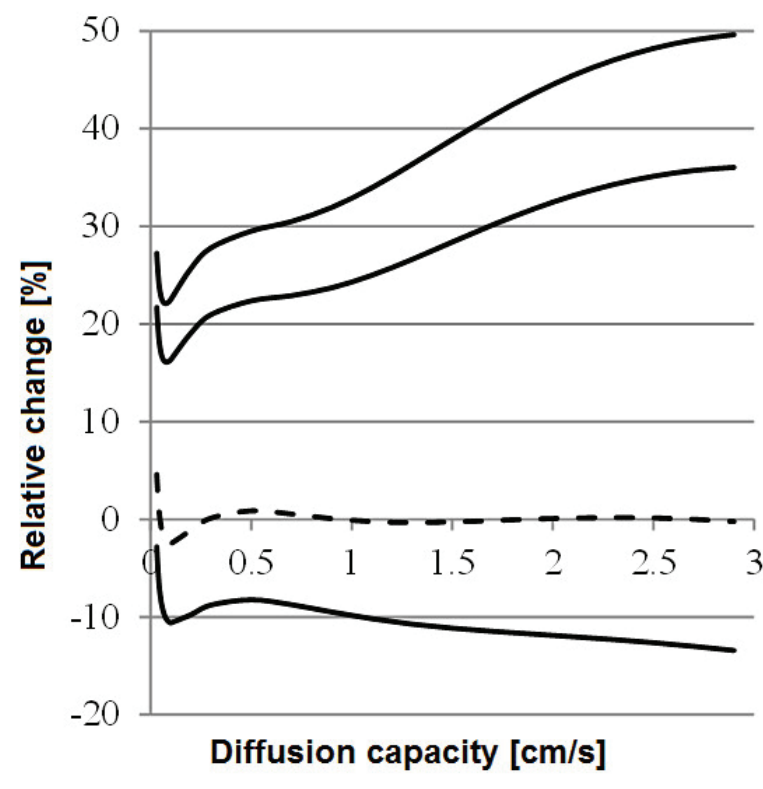

Figure 2. Relative changes in diffusion capacity as a result of including temperature and pressure effects in the calculation model. The dashed line, at standard conditions, represents the relative error due to the polynominal approximation of the inverse model.

configuration, for example with respect to the chamber geometry, require the determination of a new polynomial and there is no guarantee that the approximation error will be similar in sign or magnitude to the one shown in Figure 2. This may lead to differences between values obtained on different instruments or even on the same instrument in a different configuration.

In the range of $\mathrm{CO}_{2}$ concentrations of interest, the relation between the $\mathrm{CO}_{2}$ concentration and the diffusion capacity is monotonously increasing, which greatly facilitates the use of numerical methods to iteratively calculate the diffusion capacity from the $\mathrm{CO}_{2}$ concentration using the model of equations [1-7] instead of a polynomial. Even very simple methods such as a bisection method will provide a more precise diffusion capacity value over the entire range of interest than polynomial [8] and may therefore be preferred.

\section{Pressure and temperature effects}

If the temperature or pressure deviates from standard conditions, the differences between the two models are substantial. As an example, shown in Figure 2, a temperature of $304 \mathrm{~K}$ and a pressure of $85 \mathrm{kPa}$ may lead to relative differences in the diffusion capacity between $20 \%$ and $50 \%$ over the entire range. Under these conditions the estimated diffusion capacity will always be higher than the true diffusion capacity, which indicates that changes in the molecular motion dominate over other effects such as changes in the chamber geometry.

As a consequence these results highlight the importance of providing gases to the measurement chamber which have been properly conditioned to standard temperature.

Comparing the line in Figure 2 for $\mathrm{T}=296.15 \mathrm{~K}$ and $\mathrm{p}=85 \mathrm{kPa}$ with the dashed line for standard conditions we can see that pressure deviations may contribute substan- tially to these differences, probably even more than temperature deviations. While the temperature is frequently controlled in a laboratory and can be controlled rather precisely, the pressure will often simply depend on ambient air pressure. Consequently, for sudden changes in weather conditions or when using the instruments at high altitudes polynomial [8], which applies only to a pressure in the measurement chamber of $101.325 \mathrm{kPa}$, may lead to substantial errors in the diffusion capacity values.

In current instrument configurations the $\mathrm{CO}_{2}$ simply flows out of the measurement chamber into the ambient air, sometimes after passing through a valve to adjust the differential pressure between the two sides of the paper. This means that the absolute pressure in the measurement chamber is always close to the ambient pressure and cannot be controlled. A modification of the instrument which allows pressurization of the measurement chamber to a controlled level slightly above ambient air pressure, for example to $120 \mathrm{kPa}$ or $150 \mathrm{kPa}$, might eliminate the dependence on ambient pressure. Of course such pressurization will affect the diffusion processes in the measurement chamber, particularly through its influence on the free gas diffusion coefficient. The proposed model might then be used to compensate this effect.

The line for $\mathrm{T}=288 \mathrm{~K}, \mathrm{p}=105 \mathrm{kPa}$ in Figure 2 indicates that low temperature or high pressure may lead to an underestimation of the diffusion capacity values, which is in line with the theoretical considerations on the free gas diffusion discussed above. With a standard pressure of $101.325 \mathrm{kPa}$, however, there is less chance that actual pressures in the laboratory will be significantly higher than the standard pressure, so that negative relative differences are generally less likely to occur.

Finally, an important conclusion from the entire investigation is that a properly stated diffusion capacity value should include the temperature and pressure for which it is intended to be valid.

\section{CONCLUSIONS}

The dependence of diffusion capacity values on deviations of temperature and pressure from standard conditions was theoretically investigated. An existing model which describes the measurement process and allows the calculation of the $\mathrm{CO}_{2}$ concentration from given diffusion capacity values was modified to include temperature and pressure effects. Common instrument technology uses polynomials to approximately invert such models and to calculate the diffusion capacity from the measured $\mathrm{CO}_{2}$ concentrations. The results show that such a polynomial can cause relative approximation errors of up to $10 \%$, particularly in the low diffusion capacity range, which may be an issue for lower ignition propensity cigarette papers. Inversion of the model by simple iterative methods, such as a bisection method, may therefore be preferred over a polynomial approximation.

These polynomials also do not include temperature and pressure effects. A model which includes temperature and pressure effects was proposed and the changes due to the inclusion of temperature and pressure effects were determined by numerical evaluation over a temperature range 
from $288 \mathrm{~K}$ to $304 \mathrm{~K}$ and a pressure range from $85 \mathrm{kPa}$ to $105 \mathrm{kPa}$. The results show that deviations of temperature and pressure from standard conditions caused relative differences up to $50 \%$. It may therefore be advisable to use models which include temperature and pressure effects when reliable diffusion capacity values shall be reported, particularly if the actual measurement took place under other than standard conditions.

Although the proposed model may be useful for this purpose, it requires a good correspondence to the physical reality, which was not checked within the scope of this theoretical study. Consequently, even more preferably than compensating such deviations by calculation, they should be avoided by conditioning the gases flowing in the instrument and by controlling the pressure in the measurement chamber.

\section{REFERENCES}

1. Eitzinger, B.: Design Guidelines for Papers for Low Ignition Propensity Cigarettes; Presentation at the CORESTA Congress, Abstract SSPT09, Kyoto, Japan, 2004.

2. Eitzinger, B. and H. Giener: The Effect of Thermal Decomposition of Banded Cigarette Paper on Ignition Strength Test Results; Presentation at the CORESTA Congress, Abstract SSPT23, Shanghai, China, 2008.

3. Hesford, M., P. Case, S. Coburn, J. Larochelle, J.-C. Cabral, Y. DeGrandpré, and J. Wanna: A Factorial Experimental Design to Investigate the Influence of Band Diffusivity and Filler, Fibre and Citrate Contents on the Machine Smoking Yields and LIP Performance of Banded LIP Papers; Presentation at the CORESTA Congress, Abstract SSPT07, Edinburgh, UK, 2010.
4. Drake, D.G., D.S. Riley, R.R. Baker, and K.D. Kilburn: On a Cell to Measure Diffusion Coefficients of Gases Through Cigarette Papers; Int. J. Heat Mass Transfer 23 (1980) 127-134.

5. CORESTA: CORESTA Recommended Method No. 77. Determination of Diffusion Capacity by Measurement of $\mathrm{CO}_{2}$ Transfer Rate Through Materials Used as Cigarette Papers and Cigarette Papers Having an Oriented Zone of Reduced Diffusion Capacity; 2014, Available at http://www.coresta.org/Recommended_ Methods/CRM_77.pdf (Accessed June 2014).

6. International Organization for Standardization (ISO): ISO 187:1990. Paper, Board and Pulps -- Standard Atmosphere for Conditioning and Testing and Procedure for Monitoring the Atmosphere and Conditioning of Samples; ISO, Geneva, Switzerland, 1990.

7. Norman A.B., J.C. Caudle, and C.W. Henderson: Measurement of Gas Diffusion Capacity of Cigarette Papers; Beitr. Tabakforsch. Int. 21 (2005) 425-434.

8. Lide, D.R., ed.: Handbook of Chemistry and Physics, 86th Edition, CRC Press, Boca Raton, FL, USA, 2006.

9. Astl, G.: Cigarette Paper - A Porous Membrane; unpublished internal results from permeability measurements with Argon, Helium and Nitrogen (2003).

\section{Corresponding author:}

Bernhard Eitzinger

delfortgroup $A G$

Fabrikstrasse 20

4050 Traun, Austria

E-mail: Bernhard.Eitzinger@delfortgroup.com 